\title{
CUIDADOS PALIATIVOS COM ÊNFASE EM CONFORTO
}

\author{
PALLIATIVE CARE WITH EMPHASIS ON COMFORT
}

\section{Ana Flávia Cirilo Costa ${ }^{\mathrm{I}}$}

RESUMO: O presente tema em específico "Cuidados Paliativos com Ênfase em Conforto" foi discorrido com a finalidade de revisão integrativa literária, portanto, neste artigo foram apresentados conceitos dos cuidados e estratégias destinados ao paciente com em cuidados paliativos seja domiciliar ou hospitalar, em especial, a assistência dos profissionais de Enfermagem nesse âmbito. Como reportado o presente artigo é uma revisão integrativa literária, de modo que, demais artigos no requisito referencias é unicamente exploratório, para auxilio da execução deste artigo. Foram bases para o presente artigo 5 artigos sobre o mesmo tema, com foco na resolução-problema, neste artigo foi apresentado o conceito de cuidados paliativos com ênfase no conforto do paciente através de educações ea importância extrema do profissional de Enfermagem nesse momento delicadopara o enfermo e familiares.

Palavras-chave: Cuidados Paliativos. Atenção à saúde. Assistência ao paciente, Enfermagem.

ABSTRACT: This specific topic "Palliative Care with Emphasis on Comfort" will be discussed with the purpose of an integrative literary review, therefore, in this article we will present concepts of care and strategies for the patient with this diagnosis, whether at home or hospital, in particular, care of nursing professionals in this area. As reported, this article is an integrative literary review, so that other articles in the reference requirement is only exploratory, to aid in the execution of this article. Five articles on the same topic were the basis for this article, focusing onproblem solving, in this article we will present the concept of palliative care with an emphasis on patient comfort through education and the extreme importance of the nursing professional in this delicate moment for the sick and family members.

Keywords: Palliative care. Health care. Patient care. Nursing.

\section{INTRODUÇÃO}

Segundo a Organização Mundial de Saúde (OMS), os cuidados paliativos são um conjunto de cuidados, feitos para o indivíduo que sofre de uma doença graveou incurável, com o objetivo de aliviar o seu sofrimento, melhorando o bem-estare a qualidade de vida.

\footnotetext{
Graduação de Enfermagem, pela Faculdade Pitágoras Campus Betim. E-mail: anaflaviacirilo9@gmail.com.
} 


\begin{abstract}
Os cuidados paliativos ainda se encontram em processo de construção, motivo pelo qual a maior parte das estratégias de ação ainda são desafiadoras e requerem a atenção de uma equipe interdisciplinar. Por isso, essa abordagem não se restringe à mera execução de procedimentos em pacientes, mas à propagação da preocupação, interesse, interação e compromisso pelo cuidado. (VASCONCELOS, B; PEREIRA, P., 2018)
\end{abstract}

Ou seja, estes cuidados em específico não se trata apenas da doença em si, mas, também dos seus eventos adversos como um todo. Os tipos de cuidados podem ser envolvidos como: físico, psicológicos, sociais e espirituais, todas estas ponderações devem ser realizadas pela equipe multidisciplinar ao paciente com este diagnostico, mesmo o enfermeiro sendo o principal alicerce destes cuidados.

A dor é um dos sinais e sintomas que o paciente com câncer mais apresenta e relata. O seu controle para o alívio do desconforto e sofrimento é uma das preocupações mais presentes no dia-a-dia do enfermeiro que trabalha com esse tipo de paciente, principalmente, nas unidades de cuidados paliativos. (REIBNITZ, K.; WATERKEMPER, R., 20I0)

A avaliação da dor é de suma importância neste processo, principalmente em pacientes oncológicos em cuidados paliativos, desse modo, o enfermeiro que atua em cuidados paliativos, como indivíduo cuidador, deve buscar através de seus conhecimentos, amenizar ou eliminar qualquer tipo de desconforto que o paciente possa sentir e/ou que a família relate dependendo da complexidade docaso, como por exemplo, a dor seja intensa/constante ou não.

De acordo com dados apresentados pela OMS, no Brasil a estimativa de pessoas que necessitam destes cuidados paliativos é eminente, porém, recorrem a estes cuidados apenas na fase final da vida, como demonstra na citação a seguir:

Uma estimativa da OMS (apud Bomfim) mostra que, no Brasil, entre 521 mil e 536 mil pessoas necessitam de cuidado paliativo, no entanto, esses tendem a ser indicados somente na fase de final de vida, restringindo a atuação das equipes especializadas nesta área. (VASCONCELOS, B; PEREIRA, P., 2018)

Este cenário representa a maneira que determinados indivíduos reagem ao diagnóstico, de forma que, podem estar sentindo os sintomas sem ter o devido conforto, e cuidados específicos dos profissionais. Com isso, tem correspondido a escassez de serviços á atenção domiciliar para esta especialidade. Portanto, não é verdade que estes cuidados são feitos quando já não há mais "nada o quefazer", pois ainda podem ser oferecidos cuidados essenciais para o bem-estar equalidade de vida 
da pessoa, independente do seu tempo de vida. Os cuidados paliativos também servem para cuidar e dar apoio aos pacientes oncológicos e aos familiares, devido à complexidade do quadro e momento delicado na vida de todos os envolvidos, ao oferecer apoio em relação a como devem ser a execuçãodos cuidados, a resolução de dificuldades sociais e para uma melhor aceitação e compreensão do luto, situações como dedicar-se ao cuidado de alguém ou lidar a possibilidade de perder uma pessoa querida são difíceis e podem causar muito sofrimento nos familiares. As orientações destes cuidados devem ser cordiais e fidedignas, o enfermeiro promove educação em saúde, orientações, apoio emocional e social aos pacientes e seus familiares, visto que, podendo serum diagnóstico de difícil aceitação e compreensão dos envolvidos como exemplo, paciente e familiares. A seguinte citação irá definir de forma sucinta o significado de cuidados paliativos, para melhor entendimento destes cuidados e classificação dos pacientes inseridos neste contexto.

Entende-se por cuidados paliativos todo cuidado ativo e global realizado a pacientes cuja doença não respondeu ao tratamento curativo, e que estão sob o controle da dor e de outros sintomas como: problemas psicológicos, sociais e espirituais, com o propósito de alcançar maior qualidade de vida para o paciente e sua família. Desta forma, são cuidados proporcionados aos pacientes que não responderam ao tratamento curativo e necessitam de cuidados para ocontrole de sinais e sintomas da doença. (REIBNITZ, K.; WATERKEMPER, R., 2010)

Neste sentido, a educação do enfermeiro ao paciente tem se mostrada a porta de entrada para bons resultados, sendo uma estratégia de ação destes profissionais, evitando possíveis eventos inesperados no decorrer do processo como um todo, desde cuidados domiciliar á hospitalar, ressaltando que a educação se trata de todos os aspectos do paciente envolvido neste diagnóstico. Os enfermeiros, nos cuidados paliativos, definem qualidade de vida como o principal objetivo desses pacientes, oferecendo meios que garantam mais vidasaos anos, ao invés de anos à vida.

A comunicação, especialmente de notícias difíceis, é outro pilar de majoritária importância. Deve-se buscar a comunicação aberta e ativa, em um processo de confiança e vínculo com o paciente e a família, considerando-se sempre a disponibilidade de informações através da verdade lenta e progressivamente suportável. (OTHERO, M.; GOMES, A, 2018.)

A relação construída nesse âmbito entre o enfermeiro e paciente-familiares vai 
além do controle álgico e protocolo médico, o atendimento holístico é uma das atribuições do enfermeiro, assim, orientando de forma eficaz e adequada para sua equipe técnica, esses cuidados devem ser realizados até o pós morte, sendoo momento que a família mais precisa de compreensão e empatia destes profissionais, a comunicação entre todos auxilia o próprio processo de aceitaçãoda morte. De acordo com a OMS (Organização Mundial de Saúde):

\footnotetext{
Pontua ainda que se deve iniciar o tratamento paliativo o mais precocemente possível, concomitantemente ao tratamento curativo, utilizando-se todos os esforços necessários para melhor compreensão e controle dos sintomas. E que ao buscar o conforto e a qualidade de vida por meio do controle de sintomas, pode-se também possibilitar mais dias de vida (OMS, 2007). (OTHERO, M.; GOMES, A, 2018.)
}

Desta forma, facilita o norteamento sobre a assistência diante os cuidados paliativos, validando as seguintes questões: o paciente deseja ser compreendido como um ser de emoções e sofrimento físico, com necessidades de fármacos/drogas para a resolução dos sintomas tantos físicos quanto mentais, etecnologias avançadas para identificar alterações que não podem ser vistas de forma "superficial", enfatizando o enfermeiro, devido suas atividades assistenciais são de fundamental importância, desde cuidados físicos á conversas sobre medos e aflições de seus pacientes. De acordo com pesquisas de satisfação realizadas em um hospital em específico sem ser citado e exposto muitos pacientes internados relatam que durante sua estadia nas UIN's (Unidades de Internações), se sentem confortáveis, acolhidos e esperançosos sobre o tratamento devido a interrelação dos profissionais de saúde e principalmente a empatia que ocasiona uma diversidade de sensações positivas no paciente. Uma observação importante descrita em um dos artigos, pontua sobre o início dos cuidados paliativos precocemente e sua ação sobre o enfermo, mostrando grande significância de uma boa assistência de Enfermagem e o cuidado como um todo.

\footnotetext{
Assim, torna-se possível elencar como principais norteadores daassistência em cuidados paliativos: prevenção e controle de sintomas; intervenção psicossocial e espiritual; paciente e família como unidade de cuidados; autonomia e independência, comunicação e trabalho em equipe multiprofissional. (OTHERO, M.; GOMES, A, 2018.)
}

A educação e orientações preconizadas pelos Enfermeiros aos pacientes, tem 
grande eficácia em um processo menos doloroso para o enfermo e seus familiares, a assistência de Enfermagem abrange o paciente como um todo, desde aspectos físicos á emocionais, ressaltando o atendimento holístico do paciente. Contudo, entretanto, o objetivo geral deste artigo se baseia na ênfaseem conforto destinadas a pacientes em cuidados paliativos sem especificação de âmbito, a hipótese manifestada neste artigo através de pesquisas levantadas criteriosamente sobre o tema, baseou-se em cinco artigos científicos e de revisão literária, tem em consideração o conteúdo de suma importância para todos os profissionais da saúde sem exceção.

\section{DESENVOLVIMENTO DA REVISÃO DE LITERATURA}

Para levantarmos informações originando a execução do presente artigo, utilizamos o Google Acadêmico, foi necessário a leitura de vinte artigos no total, porém, como preconizado, escolhemos cinco artigos que mais descreviam o tema de forma esclarecedora e completa, buscamos as seguintes questões em específico: cuidados paliativos, atenção à saúde, assistência ao paciente e enfermagem. A partir das questões norteadoras, mediante o emprego dos descritores citados acima, conseguimos localizar centenas de artigos, foram selecionados também de acordo com o ano de publicação, referências bibliográficas, tipo de estudo, objetivo principal, resultados. Trata-se de estudo qualitativo, exploratório e descritivo, o cenário de pesquisas foram cinco artigos como citado acima, o desenvolvimento deste artigo esclareceu e incentivou a compreensão e a prática dos profissionais de enfermagem sobre os cuidadospaliativos, demonstrando que suas ações desde assistência física e emocional tem grande impacto na vida do enfermo e familiares.

O desenvolvimento deste artigo como revisão de literatura, é destinado para profissionais da saúde, em especial aos enfermeiros atuando nessa especialidade/setor, para que as ações de enfermagem em cuidados paliativos priorizem a promoção do conforto ao paciente, de forma resumida, os cinco artigos retratam muito bem ações da enfermagem e as intervenções paliativas, quando selecionados foram lidos novamente, para validar as informações do tema em foco e discorrermos de forma relevante e fidedigna, a data de publicação destes artigos 
foram essenciais devido ao tempo de avanço das pesquisas dos cuidados paliativos, os artigos nomeados compõem a data de publicação a partir do ano de 2010, a maioria dos estudos são revisões bibliográficas ou de abordagem qualitativa. A partir de todas as análises de inserção para fonte da pesquisa exploratória, este artigo foi projetado, dentre o enfoque dos artigos buscados, o mais estudado foi a assistência da enfermageme a educação ao paciente vinda dos enfermeiros(as).

De todas as análises dos artigos em questão, destacaram as seguintes palavras descritoras: Cuidados Paliativos, Atenção à saúde, Assistência ao paciente, Enfermagem. Neste estudo foram contempladas três categorias temáticas, os cuidados paliativos, a ênfase em conforto e a enfermagem como profissional em especial, com o intuito de preconizar sobre estes cuidados e a ação da Enfermagem sobre a vida do enfermo e seus familiares.

\section{CONSIDERAÇÕES FINAIS}

Refletir sobre a temática cuidados paliativos, abrangem muitas questões desde a descoberta do diagnóstico até a pós morte, os cuidados dos enfermeiros na assistência ao paciente em cuidados paliativos com o objetivo de contemplar aênfase em conforto, incluindo todos os quesitos desde físicos á espirituais, que também envolvem conforto. Neste sentido, a pesquisa exploratória demonstrou como relevância a educação ao paciente-família vinda dos enfermeiros, e a ênfase em conforto do enfermo e também aos familiares envolvidos nestas situações, este estudo serve também para enfatizar a importância de um bom planejamento da assistência e o papel da enfermagem, que por sinal tem se revelado bastante fundamental nestes casos, a equipe multiprofissional também é de importância, destacamos os enfermeiros devido ao maior tempo de cuidados com estes pacientes e impacto positivo na vida deles.

De acordo com os artigos abordados e utilizados como pesquisa exploratória, apesar de ser pouco introduzida e difundida esse conceito no Brasil, se torna extremamente importância o contato dos profissionais da Enfermagem ou demais, com artigos seguindo esta mesma temática, para assim melhor entendimento dos 
cuidados especializados e a educação para todos envolvidosoriginando melhor gestão de riscos, assistências e conforto ao paciente e familiares. A assistência de Enfermagem promove o conforto em geral para os pacientes e seus familiares, até o pôs morte, sendo um dos momentos que mais precisam de atenção e acolhimento, o que torna, os enfermeiros o alvo em principal e eficaz para estas ações, entender melhor o morrer e a morte, estabelece que a assistência seja adequada e transparente, para que tudo isso

ocorra, é imprescindível uma equipe preparada e treinada para lidar com estes momentos, e se faz mais uma vez importante o papel dos enfermeiros nesta ação educativa a sua equipe.

Os efeitos decorrentes deste diagnóstico entre a vida e morte, simbolizam numa assistência mais consistente e sólida por parte dos profissionais de saúde inseridos nestes casos, lidando com as reais necessidades dos pacientes, analisando criteriosamente as prioridades de cada doente. O cuidar até o pós morte implica diretamente no conforto, para assim assegurar que o paciente nãosofra até o momento de sua partida e após também, ou seja, cuidados com o corpo e familiares, permitindo uma partida calma e serena. Diante da constatação, como sociedade e indivíduo, o seguinte fato se torna relevante, a existência de melhores condições para este modelo de cuidado, tornando essa assistência efetiva e encorporado á todos, para melhor entendimento, que a maioria da população algum dia precisará destes cuidados.

\section{REFERÊNCIAS}

ANDRADE, C. G.; COSTA, S. F. G. et al. Cuidados paliativos: a comunicação como estratégia de cuidado para o paciente em fase terminal, Rev. Scielo, Maio/2or3. Disponível em: https://www.scielosp.org/article/csc/2013.vi8ng/2523-2530/

OTHERO, M. B.; GOMES, A. L. Z. et al. Cuidados paliativos, Estud. av. 30 (88) • Sep-Dec 2016.

Disponível em: http://dx.doi.org/10.23973/ras.70.85

PALMEIRA, H. M.; COMIN, F. S.; PERES, R. S. et al. Cuidados paliativos no Brasil: revisão integrativa da literatura científica, Aletheia no. 35-36 Canoas Dez/2orr. Disponível em: http://pepsic.bvsalud.org/scielo.php?script=sci_arttext\&pid=SI413-03942011000200014

REIBNITZ, K. S.; WATERKEMPER, R. et al. Cuidados paliativos: a avaliação da dor na percepção 
de enfermeiras, Revista Gaúcha Enfermagem, 3I de Março de 2010. Disponível em: https://doi.org/10.1590/S1983-1447201000o10oor2

VASCONCELOS, G. B.; PEREIRA, P. M. et al. Cuidados paliativos em atenção domiciliar: uma revisão bibliográfica, Rev. Adm. Saúde - Vol. ı8, № 70, jan. - mar. 2018. Disponível em: http://dx.doi.org/ro.23973/ras.70.85 